\title{
Retinal Vein Occlusion
}

National Cancer Institute

\section{Source}

National Cancer Institute. Retinal Vein Occlusion. NCI Thesaurus. Code C34981.

An occlusion of the retinal vein. 